\title{
Should we continue population-based cervical cancer screening programme in Poland? A statement in favour
}

\author{
Andrzej Nowakowski ${ }^{1,2,3}$, Maryla Turkot ${ }^{1}$, Kinga Miłosz ${ }^{1}$
}

\begin{abstract}
Organised cervical cancer screening programme in Poland introduced in 2006/2007 has never been optimal, largely due to low participation rate. However, recent analysis of trends in the burden of cervical cancer mortality revealed an acceleration of the downward trends in women of the screening age 25-59 around the time of the introduction of the programme. Possible factors responsible for this phenomenon include dissemination of Pap testing (mainly in opportunistic screening) and attempts to assure higher quality of screening procedures, which accompanied the roll-out of the screening programme. Despite the obvious flaws and limitations of the programme, its discontinuation might result in adverse epidemiological, clinical and financial outcomes related to limiting the screening to the opportunistic mode only. Therefore the programme requires continuation and improvements. Unfavourable trends in the burden of the disease in older women require rising the upper age limit for screening to facilitate access to screening. Several strategies to raise participation need to be tested. The inevitable advent of more sensitive but less specific, molecular HPV screening requires pilot studies, evaluation of their outcomes and adjustments before full-scale introduction at the national level. According to European Guidelines, this may be executed only within an organised screening programme.
\end{abstract}

NOWOTWORY J Oncol 2018; 68, 2: 106-110

Key words: cervical cancer, screening, organised screening programme, HPV testing, Poland

\section{Introduction}

Exfoliative cytology is the most common screening test for early detection of cervical cancer and its precursors in the developed countries around the world nowadays. It was developed by a Greek physician and scientist George Papanicolaou in the third decade of the $20^{\text {th }}$ century [1]. A Romanian scientist Aurel Babes made a similar discovery at the same time, but it was the Papanicolaou method of cell staining which became the standard in cervical cytology around the world and the cervical cytology test (the Pap test) holds Papanicolaou's name ever since. In 1925 a German gynaecologist Hans Hinselmann invented a colposcope a device still in use in the gold standard procedure of triage of women with abnormal Pap test results. In the second half of the $20^{\text {th }}$ century epidemiological observations started to indicate that cervical cancer might be caused by a sexually transmitted factor. Indeed, in 1983 Harald zur Hausen, a German virologist and his team isolated DNA of the human papillomavirus (HPV) from the tissue of cervical carcinoma [2]. A large body of scientific evidence gathered for the next decades confirmed the crucial role of genital HPV types in the pathogenesis of cervical carcinoma and Harald zur Hausen was awarded the Noble Prize for his inventions in 2008. In the 1990s lan Frazer and Jian Zhou developed and patented a technology to produce HPV viral-like-particles, which induce humoral response and form the bases of HPV vaccines. The first of them was registered by FDA in 2006 and three are currently in use around globe providing up to $70-95 \%$ protection against cervical cancer. In 2003 FDA approved the first commercial HPV test for clinical use in

\footnotetext{
${ }^{1}$ Department of Cancer Prevention, The Maria Skłodowska-Curie Memorial Cancer Centre and Institute of Oncology, Warszawa, Poland

${ }^{2}$ Institute of Health Sciences, Siedlce University of Natural Sciences and Humanities, Siedlce, Poland

${ }^{3}$ Second Department of Gynaecological Oncology, St. John's Cancer Centre of Lublin, Poland
} 
diagnosis of cervical cancer and three societies: American Cancer Society, American Society of Colposcopy and Cervical Pathology and American Society of Pathology published official recommendations on the use of HPV testing in cervical cancer screening [3].

\section{Organised, population-based cervical cancer screening programmes - lessons learnt in other countries}

Cervical cancer screening with the use of Pap testing enables detection of curable cervical cancer precursors and thus provides protection against the development of invasive disease. In most developed countries, Pap tests are performed in two different settings: as opportunistic screening and as population-based organised screening programmes. Opportunistic screening is based on collection of Pap smears when women visit gynaecological surgeries voluntarily for screening or during appointments for other reasons such as prenatal visits, contraception prescriptions etc. Population-based screening programmes are organised nationally or regionally and provide testing in accordance with an established policy which includes: invitations of women to screening, set age-ranges of the target population and intervals between the tests and measures to ensure high quality of all parts of the programme. The main characteristics of both organised population-based and opportunistic cervical cancer screening modes are presented in Table I. Organised, population-based cervical cancer screening programmes seem to be more effective and have a higher impact on the reduction of the burden of cervical cancer [4]. Some of the Scandinavian countries implemented organised Pap-smear based screening programmes as early as in 1960s. Finland followed invitational screening in all municipalities. Denmark and Sweden had partially organised screening. Within 30 years after implementation, cervical cancer mortality in those countries decreased by $80 \%$, $66 \%$ and $52 \%$ respectively. On the other hand, in Norway which followed opportunistic way of screening until 1995, the observed decrease in mortality from cervical cancer was considerably less at the level of $40 \%$. Another example of high effectiveness of population-based organised screening is the United Kingdom. In the UK, opportunistic cytological screening was present since the 1960s, but an organised programme including a call/recall system and quality assurance started in 1988. Before 1988, mortality and incidence from cervical cancer decreased by $1-2 \%$ per year, whereas after 1988 the decrease accelerated to around $7 \%$ annually. At the same time mortality rate from cervical cancer increased in the Republic of Ireland where there was no organised screening programme.

\section{Recommendation of the Council of the European Union on cancer screening}

Based on the success of implemented organised screening programmes and on the results of scientific studies, on December 2, 2003, the Council of the European Union issued Recommendation on cancer screening [5] for the Member States. In view of this document, organised screening programmes should be run for cervical, breast and colorectal cancers. Amongst the most important issues of the Recommendation were: a) consideration of various (ethical, social, medical, organisational and economic) aspects before the programme commencement, b) programme cost-effectiveness, c) centralised data system and linkage with cancer registry, d) protection of personal data, e) quality assurance and evaluation, $\mathrm{f}$ ) adequate personnel training, $\mathrm{g}$ ) equal access to screening. The Council Recommendation also invited the EU Commission to report on the implementation of cancer screening programmes, to encourage cooperation between the Member States in research and exchanging best practices. Finally, it recommended the development of new guidelines or updating of the existing guidelines for cancer screening.

\section{European Guidelines for Quality Assurance in Cervical Cancer Screening}

In 2008 a representative group of experts published the second edition of the European Guidelines for Quality

Table I. Selected major characteristics of organised population-based cervical cancer screening programmes and opportunistic screening

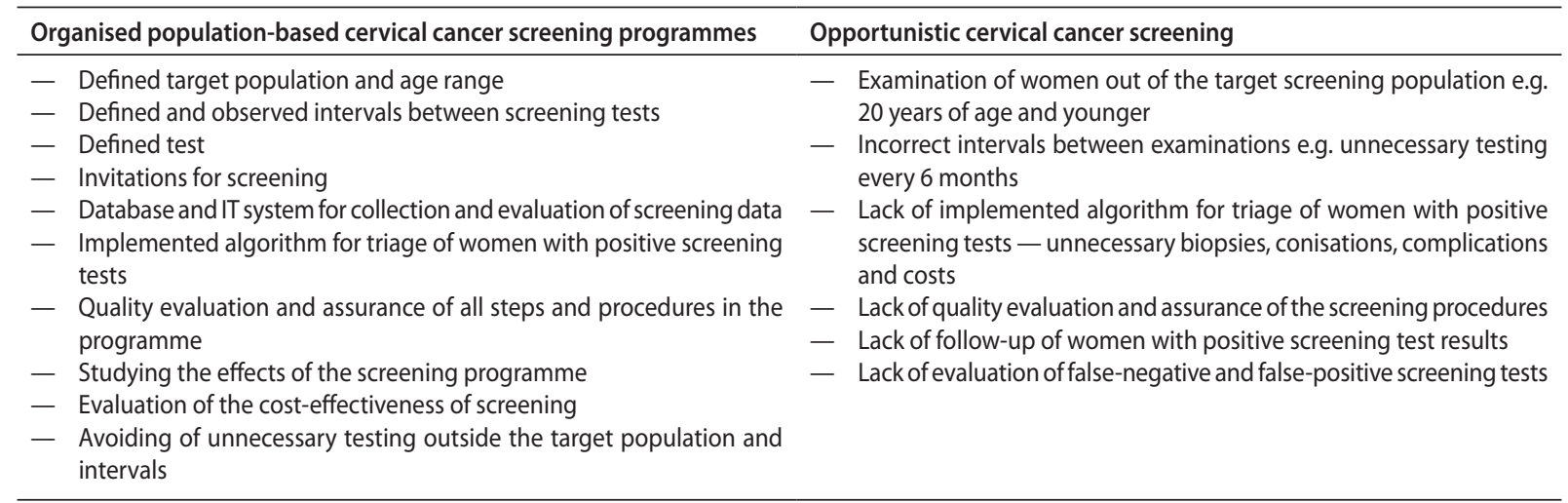


Assurance in Cervical Cancer Screening [4]. This comprehensive document encompassed all aspects of organisation of population-based cervical cancer screening programmes in the European Union and also touched on HPV vaccination, which was about to be introduced in Europe at that time. The guidelines stressed that cytological screening can prevent four out of five cases of cervical cancer, but only if the screening is provided in organised, population-based programmes with quality assurance at all levels.

The guidelines, similarly to EU Council recommendations, indicate that screening should be undertaken as a public health intervention with identification and personal invitation of each woman in the eligible population. All the steps of the screening process as well as methods of quality assurance, monitoring and evaluation should be well defined by the programme policy and regulations at the regional and national level. At the time of publication the guidelines the screening test recommended by the experts was either conventional or liquid-based cytology performed every three to five years in case of normal results. The screening should start between the age of 20-30 and continue to the age of 60-65. The opportunistic way of screening dependant on the initiative of the individual women or her doctor was discouraged by the guidelines. Such activities induce high coverage in selected parts of the population which are screened too frequently, coexisting with a low coverage in other population groups with less socioeconomic status, and heterogeneous quality, resulting in limited effectiveness and poor cost-effectiveness. The guidelines also clearly indicate that new technologies should be tested within the organised screening mode and piloted before implementation.

\section{The course of the organised cervical cancer screening in Poland and its potential impact on the epidemiology of cervical cancer}

Organised cervical cancer screening programme in Poland was first initiated in 2006. From the beginning of 2007, medical records of all procedures in the programme are recorded in the electronic database called SIMP (Polish: System Informatyczny Monitorowania Profilaktyki). Target age of women was set at 25-59 years and 3-year interval between normal tests was established. Between 2006 and 2015 the programme was coordinated by a central and regional coordination centres, which mailed personal invitations for screening tests and were responsible for other aspects of the programme execution. The programme was partially concordant with the European Guidelines in terms of policy and organisation [6]. From the beginning of 2016, regional coordinating centres were shut down and the duties of the central coordination centre were limited to some aspects of quality assurance and audits. Mailing personal invitations was stopped and the programme became semi-opportuni- stic. Low coverage ranging from $21 \%$ to $27 \%$ has been the major problem in the programme. At the same time high burden of opportunistic screening (possibly overscreening in certain cohorts) has been taking place [6]. Despite those obstacles, incidence of and mortality from cervical cancer have been decreasing with a possible acceleration of the downward trends around the 2006/2007 when organised screening was implemented. These positive trends are evident in the screening age cohorts (25-59 years). They might be potentially related to attempts to maintain/improve quality of the screening procedures and most probably to dissemination of Pap tests, performed mainly within opportunistic screening. According to questionnaire-based data from the Central Statistical Office in Poland, up $83 \%$ of women aged 20-59 declare having undergone Pap testing in the recent 3 years (Fig. 1) and this rate increased over a decade [7-9]. It is therefore possible that introduction of the organised programme and accompanying awareness campaigns resulted in dissemination of Pap smears, majority of which is performed in opportunistic screening. Unfortunately, the downward incidence and mortality trends stopped in women $60+$ years of age [10] and this requires prompt actions with focus on elderly women. Rising of the upper age limit of screening to at least 65 years of age should be promptly considered.

\section{The future of cervical cancer screening - human papillomavirus testing in organised programmes}

Although Pap smear revolutionised secondary prevention of cervical cancer, it is not a perfect screening test. Its evaluation is subjective and performer-dependant and sensitivity rarely exceeds $70-80 \%$ [4]. Recognition of the aetiological role of HPV in the development of cervical cancer and presence of the viral DNA in precancerous and cancerous cervical tissue enabled elaboration of diagnostic HPV tests, first of which was approved by the FDA in 2006 for clinical use. Since then, numerous technologies aimed at detection of oncogenic HPVs have been marketed and in 2012 three influential societies in USA published joint recommendations on the use of HPV testing (co-testing with cytology) for primary screening of cervical cancer [3]. A substantial body of scientific evidence on the use of HPV testing in screening was collected over the next years and a supplement to European Guidelines for Quality Assurance in Cervical Cancer Screening was published in 2015 [11]. This comprehensive document is largely dedicated to this new technology in cervical cancer screening. The main advantage of molecular HPV testing over cytology is its great sensitivity approximating 99-100\%. High negative predictive value of HPV tests enables extending intervals between screening rounds to 5 or even 10 years. However, lower specificity and positive predictive value of HPV testing especially in young $(<30$ years of age) women carries a risk of increased rates 
of colposcopy referrals, biopsies, excisional diagnostic and therapeutic procedures resulting in overdiagnosis of regressive lesions, overtreatment, adverse obstetrical outcomes and high costs. Also, algorithms for women with a positive HPV test have not been fully elucidated and adopted in clinical settings. Therefore HPV-based screening requires high level of organisation of the screening programme to avoid substantial increase in the number of women with positive test results and additional diagnostic and therapeutic procedures of no benefit to participating women [11]. HPV testing should not be offered in opportunistic screening. Many organisational, logistic, economic, clinical factors and considerations should be take into account before introduction of HPV-based screening [11]. Implementation of this service should be performed gradually, with pilot testing and evaluation before full-scale roll-out.

\section{Why organised screening in Poland?}

Although the course of the organised screening programme in Poland, mainly due to low participation rate, has never been optimal, there are several arguments for continuation of the programme and its modification rather then discontinuation.

a) Recent analysis suggests that descending trends in the burden of cervical cancer accelerated after implementation of the screening programme [6].

Discontinuation of the programme might cause adverse epidemiological outcomes and rise in cervical cancer burden in the country. Access to screening cytology might become more difficult especially to women with lower socioeconomic status, who cannot afford private gynaecological care.

b) Actions are required to implement effective ways of rising participation in the screening programme.

Two years ago by the decision of the Ministry of Health, mailing of personal invitations to screening cytology (and mammography) was stopped. The arguments were high costs, lack of effectiveness, issues with access to personal identification data and consenting. There is a need to evaluate different modes of rising participation in the programme (e.g. telephone and direct contacts with women by family midwives, mailing personal invitations) and implement the most effective strategy. Such initiatives may be fully evaluated only within a setting of the organised screening.

c) Action is needed to reach high-risk older women with screening procedures.

Recent analysis indicates arrest of the decreasing trends in cervical cancer burden in women aged 60 years and above in Poland. Prompt action is required to elicit awareness of older women and facilitate access to screening procedures by raising the upper age limit of the programme to at least 64 years.

d) Action is required to decrease potentially cost-ineffective opportunistic screening/overscreening.

Coverage of the organised programme is very low in certain cohorts, but statistical data indicated widespread participation in Pap testing at the same time (Fig. 1). A relegation of the burden of screening procedures into the organised programme is therefore required. Certain measures to assure quality of the screening procedures are run within the programme and further are planned to evaluate and raise screening quality. Data on these measures in opportunistic screening are unknown and more difficult to obtain.

e) HPV-based screening as a more effective strategy is being introduced in some countries in the world and Poland is inevitably facing its introduction in the nearest future.

HPV-based screening should be piloted and evaluated before full-scale introduction. According to the Supplements to European Guidelines for Quality Assurance in Cervical Cancer Screening published in 2015 pilot, evaluation,

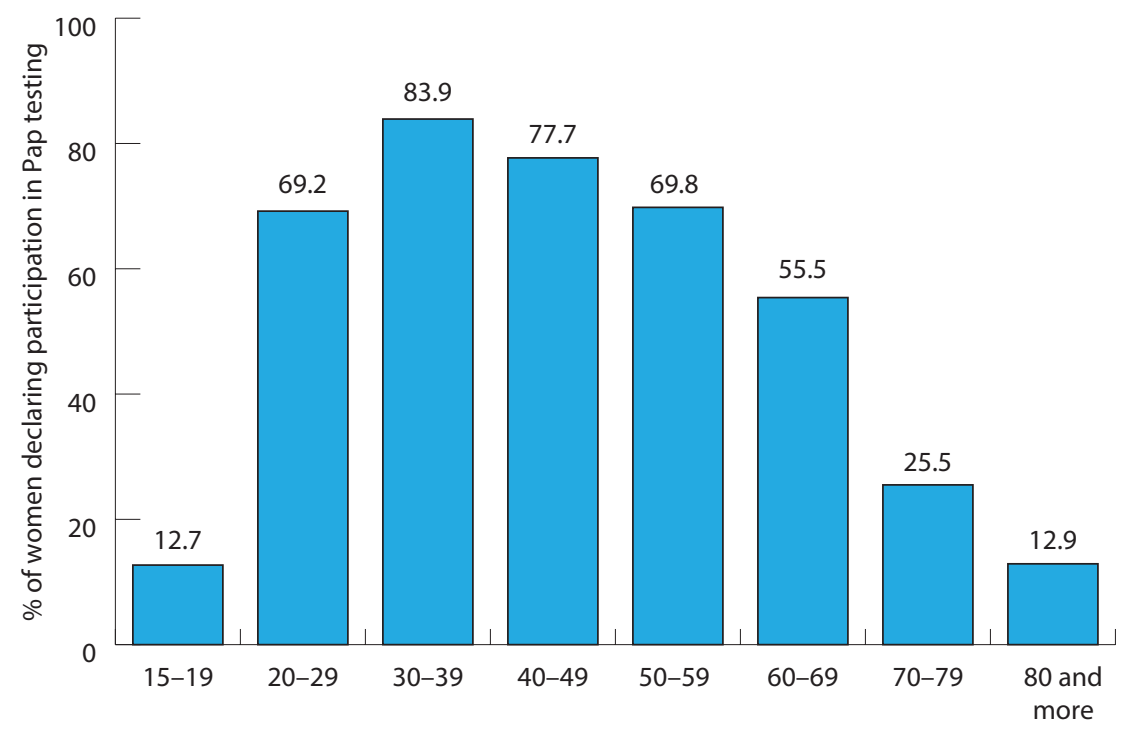

Figure 1. Questionaire-based data on participation in cervical cancer screening within the previous 3-years among Polish women [7] 
introduction and execution of HPV-based screening should be performed in organised screening programmes only.

\section{Conflict of interest: none declared}

\section{Andrzej Nowakowski, MD, PhD}

St. John's Cancer Centre of Lublin

Second Department of Gynaecological Oncology

ul. Jaczewskiego 7

20-090 Lublin, Polska

e-mail:andrzejmnowakowski@poczta.onet.pl

Received \& Accepted: 3 Jun 2018

Based on the presentation at the VI Annual Conference of the Nowotwory Journal of Oncology, 'Oncological Debates', held in Warszawa, 6-7th April 2018.

\section{References}

1. Papanicolaou GN, Traut HF. The diagnostic value of vaginal smears in carcinoma of the uterus. 1941. Arch Pathol Lab Med 1997; 121: 211-224.
2. Durst $\mathrm{M}, \mathrm{Gissmann} \mathrm{L}$, Ikenberg $\mathrm{H}$ et al. A papillomavirus DNA from a cervical carcinoma and its prevalence in cancer biopsy samples from different geographic regions. Proc Natl Acad Sci USA 1983; 80: 3812-3815.

3. Saslow D, Solomon D, Lawson HW et al.; ACS-ASCCP Cervical Guideline Committee. American Cancer Society, American Society for Colposcopy and Cervical Pathology, and American Society for Clinical Pathology screening guidelines for the prevention and early detection of cervical cancer. CA Cancer J Clin 2012; 62: 147-172.

4. Arbyn M, Anttila A, Jordan J et al. European Guidelines for Quality Assurance in Cervical Cancer Screening. Second edition - summary document. Ann Oncol 2010; 21: 448-458.

5. Maroni R. Council Recommendation of 2 December on cancer screening. Off J Eur Union 2003(878): 34-38.

6. Nowakowski A, Cybulski M, Śliwczynski A et al. The implementation of an organised cervical screening programme in Poland: an analysis of the adherence to European guidelines. BMC Cancer 2015; 15: 279.

7. Główny Urząd Statystyczny. Stan zdrowia ludności Polski w 2014 r. Warszawa: Zakład Wydawnictw Statystycznych, 2016.

8. Główny Urząd Statystyczny. Stan zdrowia ludności Polski w 2009 r. Warszawa: Zakład Wydawnictw Statystycznych, 2011.

9. Główny Urząd Statystyczny. Stan zdrowia ludności Polski w 2004 r. Warszawa: Zakład Wydawnictw Statystycznych, 2006.

10. Nowakowski A, Wojciechowska U, Wieszczy P et al. Trends in cervical cancer incidence and mortality in Poland: is there an impact of the introduction of the organised screening? Eur J Epidemio/ 2017; 32: 529-532.

11. Anttila A, Arbyn M, De Vuyst H et al. (eds). European guidelines for quality assurance in cervical cancer screening. 2nd ed. Supplements. Luxembourg: Office of the European Union, 2015. 